\title{
SEXUAL SELECTION BY FEMALE CHOICE IN A MONOGAMOUS BIRD: DARWIN'S THEORY CORROBORATED
}

\author{
P. O'DONALD \\ Department of Genetics, University of Cambridge Downing Street, Cambridge CB2 3EH, \\ England
}

Received 19.ii.80

\section{SUMMARY}

The Arctic Skua is a seabird that is polymorphic for dark, intermediate and pale phenotypes of plumage. The melanic, dark and intermediate males can find mates sooner in the breeding season than the non-melanic, pale males. When males are looking for new mates, melanic males find mates on average four days sooner than non-melanic males. There is no difference in the breeding dates of the females, nor in the breeding dates of males who have not changed their mates. The difference in the males' breeding dates is found only on change of mate. Finding a new mate takes about six days for a dark male, about eight days for an intermediate male, and about eleven days for a pale male. These differences give the melanic males an advantage by sexual selection: exactly as Darwin had postulated in his theory of sexual selection of monogamous birds, the earlier pairs are more successful in terms of the numbers of chicks they rear to fledging. The overall disadvantage of intermediates and pales relative to darks is given by the sexual selective coefficients

$$
\begin{aligned}
s_{\mathrm{I}} & =0.014 \\
s_{\mathrm{P}} & =0.063 .
\end{aligned}
$$

The melanic males gain their advantage because the females prefer to mate with them. Models of female preference entail distributions of breeding dates that fit the data better than models of male competition. The earlier breeding of melanic males can be satisfactorily explained if 38 per cent of females prefer to mate with melanics rather than with non-melanics. In the model which fits the data best, 4 per cent of females prefer dark males and 34 per cent prefer either dark or intermediate males. Further evidence, which strongly supports the theory of female choice, is provided by the stability of the polymorphism, the existence of assortative mating, and the absence of any effect of male experience on the chances of finding a mate. The data of the Arctic Skua corroborate Darwin's theory of sexual selection by female choice in monogamous birds.

\section{INTRODUCTION}

IN the Descent of Man (1871), Darwin put forward his theory that sexual selection by female choice of mate has determined the evolution of male characters for courtship and sexual display. In polygynous birds like the ruff, peacock and pheasant, such characters have often evolved to an extreme degree. It is easy to see how they may have been strongly selected: those males with more highly developed characters, which the females prefer, may have fertilised many more females than their less attractive rivals. Thus they will have obtained a great selective advantage, and the more extreme developments of the characters will have rapidly evolved. In monogamous organisms, like the majority of birds, however, each male mates with only one female during the breeding season. Unless the preferred males can 
somehow produce more offspring than the others, no selection of the preferred characters can take place.

Darwin had a subtle and realistic ecological theory to explain how the preferred males would obtain their selective advantage. He postulated that high reproductive success would correlate with early breeding during a bird's breeding season. He associated breeding date and reproductive success with the nutritional condition of the females: better nourished females would breed earlier, lay more eggs and rear more offspring. Since the earliest females have the first choice of the males, they can mate according to their preferences. On average, therefore, the preferred males breed earlier than the others and gain selective advantage by mating with females who are reproductively more successful. Selection by female choice of mate can therefore operate in monogamous species of birds. In a recent paper (O'Donald, 1980 b) I discussed this theory in detail and analysed its evolutionary consequences mathematically.

It is now well established that, as Darwin had postulated, the reproductive success of birds depends on their date of breeding: among non-passerine birds, the earlier pairs may be much more successful than the later ones. The latest pairs to breed are usually the least successful among birds of all families. For example, in a seabird, the Arctic Skua, pairs that hatch their chicks in the first week of hatching fledge an average of 1.67 chicks; pairs that hatch their chicks in the fifth and last week fledge an average of only 0.82 chicks (O'Donald, 1972). The breeding ecology of birds thus provides the mechanism by which a selective advantage may be gained.

Do the males, whether by female choice or by fighting or other forms of male competition, actually vary in their reproductive success in accordance with the predictions of Darwin's theory? In particular, do the characters for courtship and display evolve by female choice coupled with the ecological advantage derived from having been chosen to mate early in the breeding season? This is the question I asked when I began to investigate the possibility that the polymorphism of melanic and non-melanic Arctic Skuas might be maintained by sexual selection. Having now concluded my field work which covered the periods $1959-62$ and $1973-79$, I can at last give my answer.

Arctic Skuas have been studied intensively on the island of Fair Isle in Shetland in two separate periods, 1948-62 and 1973-79. The work began in 1948 on the initiative of K. Williamson, who was the first Warden of the Fair Isle Bird Observatory. It was continued from 1959 to 1962 by P. E. Davis and myself. The results obtained during this first period of study were consistent with the theory that the melanic phenotypes (genetically the darks are homozygous and the intermediates are heterozygous) were preferentially favoured by the females and gained an advantage by breeding earlier than the non-melanic pale homozygote (O'Donald, Wedd and Davis, 1974; O'Donald, 1976; O'Donald and Davis, 1977). Among newly-formed pairs, the melanic males tend to find mates sooner and with smaller variance in breeding date than the non-melanics. If females express a preference for melanics by having a lower threshold at which they respond to the melanics' courtship, the preferential matings should come first, followed by random matings at a higher threshold. Models of the expression of female preference gave a good fit to the data of the males' breeding dates, but the data were insufficient to discriminate between models in which preferential 
matings either precede or follow random matings (O'Donald, 1976). I undertook the second period of study, 1973-79, with the help of research grants from the Natural Environment Research Council, to obtain further data on sexual selection for melanism in the Arctic Skua and thus to corroborate or refute the alternative models. Each adult bird was ringed with a colour-coded combination of rings when it first bred in the colony. It could then be identified and its matings with different individuals followed with certainty in subsequent years. Previously this had not always been done and there is some uncertainty about whether matings had changed from one year to the next. The sex of each bird and the hatching date and reproductive success of each pair were recorded on nest record cards. The colony of Arctic Skuas on Fair Isle had greatly increased in size from 1962 to 1973. Many more data have now been collected and other aspects of behaviour such as territory size have also been studied (Davis and O'Donald, 1976b). The complete data upto and including 1979 are here analysed for the first time.

To prove that sexual selection is taking place, it must be demonstrated that:

(i) some male genotypes find mates sooner than others and thus gain a selective advantage;

(ii) the differences in breeding dates between the genotypes are found only in males, not in females; and

(iii) the differences in breeding dates arise from differences in the chances of mating and are therefore found only when a male is taking a new mate, not when he mates with the same female as in previous years.

The behavioural mechanism that gives rise to selection-females choosing or males competing-is much more difficult to ascertain than the simple fact of selection itself. Both mechanisms can be stated in terms of models of mating frequencies in which a proportion of females exercise a preference for particular phenotypes. Males may compete in the intensity of their courtship. Responsive females will quickly mate with any male. Less responsive females will mate more readily with the more active or persistent males: on average they will mate later and preferentially with the more active males. In Drosophila, females of some strains are more responsive than others (Ehrman and Spiess, 1969). The more reluctant females always reject male courtship at first; several encounters with courting males may be required to elicit their mating responses. As shown by the "encounter models" of mate selection (O'Donald, 1978 $a, 1979,1980 a$ ), this behaviour will produce preferential mating between the less responsive females and the more active males. In monogamous species, preferential mating will tend to follow random matings in this model.

Females may respond at different thresholds to different males. The chances of mating will then depend on differences in the choices of the females, not on differences in the courtship of the males. Some females, who had not found a male they could quickly respond to, would mate at random with other males later. The preferential matings would thus precede the random matings. Models in which the preferential matings either precede or follow the random matings can be fitted to the sequence of matings that take place between the different phenotypes of the Arctic Skua. The better fit of 
one of these models compared to the other would therefore suggest that either female choice or male competition determined the sequence of matings.

Other independent lines of evidence may corroborate or refute the models of female choice or male competition. Assortative mating is unlikely to arise as a result of male competition. Direct observations of mating choices show that males seldom discriminate in their courtship: to produce assortative mating, males would have to compete more strongly for females who possessed the same genotype or phenotype as themselves. Assortative mating is much more likely to be a consequence of female preference: in the evolution of female preference the genes for the preference must become associated in linkage disequilibrium with those for the preferred character; the expression of preference inevitably becomes partly assortative (see O'Donald, $1980 a$, chapter 8 , for discussion of this effect).

There is a more fundamental distinction between female choice and male competition. Female choice necessarily gives rise to frequency-dependent selection: male competition does not. Males who are the object of preference gain a relatively greater advantage when they are rare than when they are common: more females will be looking for a rare male to mate with than for a common male. This "rare-male effect" (Spiess and Ehrman, 1978; O'Donald, $1978 b, 1980 a$ ) gives rise to stable polymorphism as an outcome of evolution either by sexual selection for different male phenotypes or by a balance between sexual and natural selection (O'Donald, 1977a, 1980a). Male competition can never give rise to selection with more than a slight, and then only positive, frequency-dependence (Charlesworth and Charlesworth, 1975). Polymorphism can be maintained by male competition if and only if the heterozygotes are the strongest competitors (O'Donald, $1980 a$ ). Female choice and male competition thus differ profoundly in their evolutionary consequences. I shall use evidence of the goodness of fit of models, assortative mating and the maintenance of polymorphism to show that female choice is the most probable mechanism of sexual selection in the Arctic Skua.

\section{Sexual selection in the arctic skua}

In applying the theory of sexual selection to data on the melanic polymorphism of the Arctic Skua, we must first show that sexual selection does occur and then attempt to determine its behavioural mechanism. Sexual selection occurs if the melanic males who have taken a new mate breed at different dates to non-melanic males. Breeding date has been measured by the date of hatching of the first egg. Normally a clutch of two eggs is laid, but late pairs often produce only one egg. Table 1 shows the distributions of breeding dates of males in new pairs when the breeding season is divided into six weekly intervals. Pales are very significantly later than the others. Measured in the number of days from 1st June, the mean breeding dates are as follows:

$$
\text { melanics (dark and intermediate): } \bar{x}_{M}=29.44
$$$$
\text { non-melanics (pale): } \bar{x}_{\mathrm{P}}=33 \cdot 44 \text {. }
$$

On average, the pale non-melanics are four days later in finding mates than the melanic males. These averages have been calculated for all data of new 
TABLE 1

Breeding dates of melanic and non-melanic male Arctic Skuas in new pairs

\begin{tabular}{|c|c|c|c|c|c|c|c|}
\hline \multirow{3}{*}{$\begin{array}{l}\text { Breeding dates } \\
\text { in weekly } \\
\text { intervals }\end{array}$} & \multicolumn{6}{|c|}{ Numbers of males breeding in each interval } & \multirow[b]{3}{*}{ Total } \\
\hline & Per & 19 & -62 & $\mathrm{Pe}$ & 1973 & & \\
\hline & $\mathrm{D}^{*}$ & I & $\mathbf{P}$ & D & I & $\mathrm{P}$ & \\
\hline $\begin{array}{l}\text { 10-16 June } \\
17-23 \text { June }\end{array}$ & $\begin{array}{l}1 \\
8\end{array}$ & $\begin{array}{r}2 \\
24\end{array}$ & $\begin{array}{l}1 \\
3\end{array}$ & $\begin{array}{l}1 \\
7\end{array}$ & $\begin{array}{r}2 \\
21\end{array}$ & $\begin{array}{l}0 \\
1\end{array}$ & $\begin{array}{r}7 \\
64\end{array}$ \\
\hline 24-30 June & 16 & 19 & 6 & 14 & 48 & 10 & $\begin{array}{r}04 \\
113\end{array}$ \\
\hline 1-7 July & 10 & 24 & 6 & 7 & 24 & 10 & 81 \\
\hline 8-14 July & 3 & 15 & 5 & 2 & 10 & 10 & 45 \\
\hline 15-21 July & 1 & 2 & 5 & 2 & 8 & 0 & 18 \\
\hline $\begin{array}{l}\text { Total of } \\
\text { phenotypes }\end{array}$ & & & & & & & \\
\hline \multirow{2}{*}{$\begin{array}{l}\text { Total in } \\
\text { each period }\end{array}$} & & & & & & & \\
\hline & & 151 & & & 177 & & \\
\hline
\end{tabular}

pairs shown in table 1 . There should be no heterogeneity between the averages of the two periods 1948-62 and 1973-79, for all pairs classified as new were known to be new by their phenotypes and territories. But in the earlier period, adults were not all colour-ringed and not all were positively identified from one year to the next. Some of the pairs which were classified as old pairs, having bred together in successive years, were undoubtedly new pairs. This will bias the data for old pairs, which appear to breed significantly later in the period 1948-62. But the data of new pairs will be unbiased. Table 2 shows the analysis of variance of breeding dates of individual males in new pairs in the two periods 1948-62 and 1973-79. The data for the two periods are remarkably homogeneous while the differences between the phenotypes are highly significant.

TABLE 2

Analysis of variance of breeding dates of male Arctic Skuas in new pairs in periods 1948-62 and 1973-79

Source of variation

Between periods

Between phenotypes

Interaction:

periods $\times$ phenotypes

Residual

$\begin{array}{crclc}\begin{array}{c}\text { Sum of } \\ \text { squares }\end{array} & \text { Dfs } * & \begin{array}{c}\text { Mean } \\ \text { squares }\end{array} & \begin{array}{c}\text { Values } \\ \text { of } \mathrm{F}\end{array} & \begin{array}{c}\text { Values } \\ \text { of P }\end{array} \\ 0.4877 & 1 & 0.4877 & 0.00825 & 0.928 \\ 1127.9373 & 2 & 563.97 & 9.539 & 9.45 \times 10^{-5} \\ & & & & \\ 28.7229 & 2 & 14.361 & 0.2429 & 0.784 \\ 19037.4480 & 322 & 59.123 & - & -\end{array}$

* In this table and in subsequent tables of analyses of variance, "Dfs" refers to degrees of freedom.

The test of sexual selection is made by comparing the males' breeding dates in new and old pairs. Only the new and second-year pairs can be used in this test, for third-year and older pairs always breed within a day or two of their breeding date in previous years and thus give no additional independent data on breeding date. Table 3 shows the mean breeding dates of males in new and second-year pairs and the analysis of variance of the individual values. The difference between the mean dates in second-year pairs is not significant. The corresponding difference in new pairs is highly significant as 


\section{TABLE 3}

Breeding dates of males in new and second-year pairs

(i) Mean breeding dates* of the males

\begin{tabular}{lcccc}
\hline & & & \\
& Dark & Intermediate & Pale & All phenotypes \\
New pairs & 28.33 & 29.84 & 33.44 & 30.13 \\
Second-year pairs & 21.04 & 22.55 & 21.04 & 22.00
\end{tabular}

* The mean breeding dates given in this table are the mean number of days from 1 st June to the hatching of the first egg.

(ii) Analysis of variance of breeding dates

\begin{tabular}{|c|c|c|c|c|c|}
\hline Source of variation & $\begin{array}{l}\text { Sum of } \\
\text { squares }\end{array}$ & Dfs & $\begin{array}{l}\text { Mean } \\
\text { squares }\end{array}$ & $\begin{array}{l}\text { Values } \\
\text { of } F\end{array}$ & $\begin{array}{c}\text { Values } \\
\text { of } \mathrm{P}\end{array}$ \\
\hline $\begin{array}{l}\text { Between new and } \\
\text { second year pairs }\end{array}$ & $5674 \cdot 1214$ & 1 & $5674 \cdot 12$ & $112 \cdot 115$ & $2 \times 10^{-9}$ \\
\hline Between phenotypes & 308.6767 & 2 & $154 \cdot 34$ & 3.050 & 0.0483 \\
\hline Interaction* & $405 \cdot 3556$ & 2 & $202 \cdot 68$ & $4 \cdot 005$ & 0.0189 \\
\hline Residual & $23280 \cdot 6271$ & 460 & $50 \cdot 610$ & - & - \\
\hline
\end{tabular}

shown in table 2. There is also a very significant interaction between the breeding dates of the phenotypes in new and second-year pairs. The statistical significance of this interaction is the crucial test: it shows that the later breeding of the pale males is confined to new pairs. The pales do not always breed later than the melanics: they do so only when they are having to find a new mate. Therefore sexual selection acts against them: as Darwin postulated, their later breeding date lowers their reproductive success.

In second-year and older pairs, both birds of a pair return to their previous territory. They usually arrive back within a day or two of each other. The first bird to arrive is often the male. He waits on the territory for the female. If she fails to arrive, he starts looking for a new mate. $\mathrm{He}$ associates with females on nearby territories, sometimes bringing about a divorce between another pair or mating with a female new to the colony. This takes time: the later breeding dates of new pairs reflects the time a male takes to court and mate with a new female. Second-year pairs breed at a mean date of 22 nd June. From the mean breeding dates given in table 3 , we can estimate the time required for pair formation by dark, intermediate and pale males. This is given by the mean date of breeding of these males measured from 22 nd June, since 22 nd June is the date at which they would have bred if they had not had to find a new mate. The times required for pair formation and mating are as follows.

\begin{tabular}{lc}
\multicolumn{1}{l}{$\begin{array}{c}\text { Phenotype of } \\
\text { male }\end{array}$} & $\begin{array}{c}\text { Mean number of days required } \\
\text { for pair formation and mating }\end{array}$ \\
dark & $6 \cdot 33$ \\
intermediate & $7 \cdot 84$ \\
pale & 11.44
\end{tabular}

Paie males take almost twice as long to find a new mate as the dark males. 
The times taken to find new mates may differ between experienced males, who have bred in previous years, and new males, who are breeding for the first time. If experience increases the effectiveness of courtship, experienced males should find mates rather more quickly than new males. But when a male is forced to find a new mate as a result of divorce or the death of his previous mate, his average breeding date is not significantly later than that of a male breeding for the first time. Table 4 shows the mean breeding dates of new and experienced males in new pairs and the analysis of variance of the data. Pale males with previous experience are actually slightly later than new pales, but experienced intermediates are earlier. Overall the differences are not significant.

TABLE 4

Breeding dates of new and experienced males in new pairs

(i) Mean breeding dates* of the males

\begin{tabular}{|c|c|c|c|c|}
\hline & & Phenotypes & & \\
\hline & Dark & Intermediate & Pale & All phenotypes \\
\hline $\begin{array}{l}\text { New males } \\
\text { Experienced males }\end{array}$ & $\begin{array}{l}29 \cdot 71 \\
28 \cdot 05\end{array}$ & $\begin{array}{l}32 \cdot 52 \\
27.59\end{array}$ & $\begin{array}{l}32 \cdot 88 \\
33 \cdot 21\end{array}$ & $\begin{array}{l}32 \cdot 11 \\
28 \cdot 50\end{array}$ \\
\hline
\end{tabular}

(ii) Analysis of variance of breeding dates

\begin{tabular}{|c|c|c|c|c|c|}
\hline Source of variation & $\begin{array}{l}\text { Sum of } \\
\text { squares }\end{array}$ & Dfs & $\begin{array}{l}\text { Mean } \\
\text { squares }\end{array}$ & $\begin{array}{c}\text { Values } \\
\text { of } F\end{array}$ & $\begin{array}{c}\text { Values } \\
\text { of } P\end{array}$ \\
\hline $\begin{array}{l}\text { Between new and } \\
\text { experienced males }\end{array}$ & $135 \cdot 1478$ & 1 & $135 \cdot 15$ & $2 \cdot 495$ & $0 \cdot 116$ \\
\hline Between phenotypes & $381 \cdot 5970$ & 2 & $190 \cdot 80$ & $3 \cdot 523$ & $0 \cdot 0317$ \\
\hline Interaction* & 146.0806 & 2 & $73 \cdot 040$ & $1 \cdot 349$ & 0.262 \\
\hline Residual & 9261.6762 & 171 & $54 \cdot 162$ & - & - \\
\hline
\end{tabular}

* The interaction is the difference between new and experienced males in the breeding dates of the phenotypes.

Breeding dates of new pairs are highly variable, unlike those of older pairs. As we shall see, this is to be expected when females have preferences in favour of dark and intermediate males: the pales are expected to have a long tail of late breeders extending to the end of the breeding season (fig. 1 gives the expected distributions of breeding dates according to one model of female preference). The high variance in breeding dates gives rise to large standard errors in the means for new pairs. A small interaction such as the difference between the new and experienced intermediates shown in table $4(i)$ is not likely to be found significant. The analysis of variance shows that the data of new and experienced males, not being significantly different, may be combined in order to analyse the breeding dates of the phenotypes. When the data for the periods 1948-62 and 1973-79 are combined, a total sample of dates of 328 males then gives the extremely significant differences analysed in table 2 .

So far we have analysed the breeding dates of the males in relation to their phenotypes, breeding experience and whether they were breeding in 
new or older pairs. We have assumed that sexual selection operates only between males. If the females were to show similar differences in breeding dates to those of the males, we should have to conclude that females were also subject to sexual selection. The mean breeding dates of males and females are compared in table 5(i) and the analysis of variance is given in table 5(ii). The analysis does not prove that male phenotypes differ from

TABLE 5

Breeding dates of males and females in new pairs

(i) Mean breeding dates*

\begin{tabular}{lcccc} 
& \multicolumn{3}{c}{ Phenotypes } & \\
& Dark & Intermediate & Pale & All phenotypes \\
Males & 28.76 & 29.77 & 33.03 & 30.15 \\
Females & 31.06 & 29.44 & 31.56 & 30.15
\end{tabular}

* These values are derived only from the data for the period 1973-79.

(ii) Analysis of variance of breeding dates

\begin{tabular}{lrrccc}
\hline $\begin{array}{l}\text { Source of variation } \\
\text { Between sexes }\end{array}$ & $\begin{array}{c}\text { Sum of } \\
\text { squares }\end{array}$ & Dfs & $\begin{array}{c}\text { Mean } \\
\text { squares }\end{array}$ & $\begin{array}{c}\text { Values } \\
\text { of } F\end{array}$ & $\begin{array}{c}\text { Values } \\
\text { of } P\end{array}$ \\
$\begin{array}{l}\text { Between phenotypes } \\
\text { Interaction: }\end{array}$ & 374.7811 & 1 & 1.7811 & 0.0308 & 0.861 \\
sex $\times$ phenotype & 2 & 187.02 & 3.235 & 0.0405 \\
Residual & 160.4427 & 2 & 80.221 & 1.388 & 0.251 \\
& 20115.6723 & 348 & 57.804 & - & -
\end{tabular}

female phenotypes in their breeding dates: the interaction is by no means significant. Of course, the large residual mean square, which is a consequence of the wide spread of breeding dates in new pairs, makes a real difference difficult to detect. But direct behavioural observation shows that the sexes are different and that only the males are sexually selected. Males almost always keep the same territory after they have changed mates: females adopt the territories of the males they choose to mate with. A territory is primarily defended by the male, though with help from the female after mating. Courtship is also largely a male prerogative. On this evidence, females should not be subject to sexual selection: they should not differ in their breeding dates. And, indeed, there is no significant difference in their breeding dates $(F=1 \cdot 270, P=0 \cdot 283)$, while the difference between the males is very highly significant. Our expectations are completely realised, even though the residual mean square is too large to demonstrate the statistical significance of the interaction representing the sex difference in the breeding dates of the phenotypes.

The behavioural and statistical evidence certainly justifies the inference that sexual selection acts on males but not on females. Compared to males who have kept their previous mate, those males who have had to find a new mate take an extra 7.44 days to breed if they are melanic and an extra 11.44 days if they are non-melanic. The fitness function of breeding date in relation to reproductive success is shown in table 6 (O'Donald, 1972). In new pairs, intermediate melanic males will produce 0.964 chicks for every one chick produced by a dark melanic male. Pale males will produce 0.836 
TABLE 6

Relative fledging success and breeding date of pairs of Arctic Skuas

Weeks of the breeding season

Relative fledging success

10-16 June $w=1-(0.47354-x)^{2} /(24 \cdot 254)$

17-23 June

0.99075

0.98857

24-30 June

0.90393

$1-7$ July

0.73683

8-14 July

0.48726

15-21 July

$0 \cdot 15524$

This fitness function is statistically a very close fit to the data of reproductive success of pairs of Arctic Skuas (O'Donald, 1972). It is valid for both new and older pairs, showing that the reduced reproductive success of new pairs is entirely a function of their later breeding date (O'Donald, Wedd and Davis, 1974).

chicks for every chick of a dark melanic. The relative selective disadvantage suffered by intermediate and pale males can be measured by the selective coefficients $s_{\mathrm{I}}$ for intermediates and $s_{\mathrm{p}}$ for pales, where

$$
s_{\mathrm{I}}=0.036, \quad s_{\mathrm{p}}=0.164 \text {. }
$$

New pairs constitute 38.6 per cent of all pairs (420 new pairs in a total of 1088 pairs observed). From the formulae given by O'Donald and Davis (1975), we obtain the selective coefficients for the population as a whole:

$$
s_{\mathrm{I}}=0.014, \quad s_{\mathrm{p}}=0.063 .
$$

The extra data for 1973-79 have produced slightly different values from those previously obtained.

\section{MATING Behaviour AND SEXUAL SELECTION}

Having shown that male Arctic Skuas are objects of sexual selection, the question may now be asked: what behavioural mechanism causes it? Do females choose or males compete? Evidence on the following lines may discriminate between these alternatives:

(i) goodness of fit of distributions of breeding dates to models of mate selection;

(ii) assortative mating between phenotypes;

(iii) stability of polymorphisms;

(iv) effects of male experience on breeding success.

\section{(i) Goodness of fit to models of mate selection}

O'Donald (1976) described specific models of mating preferences for the three Arctic Skua phenotypes. There are four of these models. In the simplest model, which I call Model 1, some females, who represent a proportion $\beta$ of all females, prefer to mate with melanic males: they prefer to mate with either dark or intermediate males indiscriminately and only 
mate with pale males if none of the others are available. The remaining $1-\beta$ of the females mate at random among all available male phenotypes. In Model 2, a proportion $\alpha$ of the females prefer to mate with dark males; if no darks are left unmated, they then prefer intermediates; they only mate with pale males when the others have all found mates. In Model 3 there are two groups of females with different preferences: $\alpha$ prefer to mate only with dark males and otherwise mate at random; $\beta$ prefer either dark or intermediate males; the remaining $1-\alpha-\beta$ mate at random. Finally, in Model $4, \alpha$ prefer dark males and $\beta$ prefer intermediate males. In all the models, females with preferences mate at random with available males if no males of their choice are left unmated. In any monogamous system with preferential mating, the sequence of the preferential and random matings must be specified. Mate selection appears to take place among groups of birds which have become ready to breed at the same time. We may expect that the males are ready to breed from the outset of the breeding season and are chosen by, or compete for, the females as they arrive on the breeding grounds. At successive intervals during the breeding season groups of females attain a state of readiness to breed and mate with males chosen from among those that were left still unmated at the beginning of each interval. In each interval, the preferential matings may either precede or follow the random matings or take place simultaneously with them. If the different matings take place simultaneously, this is equivalent to the arrival of the females in succession, the females choosing their mates one after the other. Models in which preferential matings precede random matings accord with the hypothesis of female choice: if females express their preference as a result of responding to the preferred males at a lower threshold than the others, preferential matings will take place first at the lower threshold, followed by random matings later at the higher threshold. Females who do not find a male they prefer then mate later at the higher threshold. The models derived from this theory of mating behaviour are called the $P$ models. Models in which the random matings are the first to take place are called the $R$ models. They would accord with the hypothesis of male competition determined by variation in the intensity or persistence of courtship: responsive females mate with any male; reluctant females mate preferentially with the more active or persistent males. The preferential matings thus follow the random matings (O'Donald, $1977 b$ ). The size of the intervals in which a group of females becomes responsive and ready to mate is a parameter of the models. When the intervals become so short that each contains only one female both $P$ and $R$ models become identical to the $S$ models in which random and preferential matings occur simultaneously: each female as she comes to breed removes one male successively.

In fitting the models to the Arctic Skua data on breeding times, it is necessary to choose a suitable interval in which the matings of the $P$ and $R$ models can take place. In section 2 , I showed that for melanic male phenotypes pair formation requires a period of about seven days, while for non-melanic males about eleven days is required. In the models I assume that courtship and mating take place in an interval of one week. This choice of interval does in fact give about the maximum likelihood fit for the $P$ and $R$ models. The weekly intervals chosen for fitting the models are those given in table 1 . The weekly totals are assumed to correspond to the proportions of females who have reached breeding condition in each week. Computer 
simulation (described in O'Donald, 1976) was then used to calculate the numbers of dark, intermediate and pale males who mated in each interval in accordance with the different models of female preference. To estimate the proportions of females expressing preferences in the models, log likelihoods were calculated for arbitrary values of the mating preference parameters $\alpha$ and $\beta$. Random perturbations were introduced into the initial values and the log likelihoods calculated again, the process continuing for a number of steps until the highest log likelihood had been found. This iterative process was itself repeated using smaller and smaller random perturbations until estimates of the parameters had been found that maximised the likelihood. The final estimates are shown in table 7. The likelihoods are also shown together

TABLE 7

Maximum likelihood estimates of female preferences according to the different models of preferential mating when fitted to the data of table 1

$\begin{array}{lcccc}\text { Model } & \text { Parameters of female preference } & \begin{array}{c}\text { Log } \\ \beta\end{array} & \begin{array}{c}\text { Support } \\ \text { likelihood } \\ \text { (to base e) }\end{array} & \begin{array}{c}\text { for } \\ \text { Model 3P }\end{array} \\ \text { 1P } & \alpha & 0.382 & -501.466 & 0.471 \\ \text { IR } & - & 0.194 & -503.292 & 2.297 \\ \text { 1S } & - & 0.286 & -502.285 & 1.290 \\ \text { 2P } & - & - & -505.277 & 4.282 \\ \text { 2R } & 0.063 & - & -505.724 & 4.729 \\ \text { 3P } & 0.026 & 0.344 & -500.995 & 0 \\ \text { 3R } & 0.039 & 0.172 & -502.842 & 1.847 \\ \text { 3S } & 0.022 & 0.260 & -501.836 & 0.841 \\ \text { 4P } & 0.026 & 0.262 & -501.120 & 0.125 \\ \text { 4R } & 0.114 & 0.132 & -503.066 & 2.071 \\ \text { 4S } & 0.057 & 0.195 & -501.997 & 1.002\end{array}$

In Models 2, 3 and 4, $\alpha$ is the proportion of females preferring dark melanic males. In Models 1 and 3, $\beta$ is the proportion preferring dark and intermediate melanic males indiscriminately, or in Model 4 the proportion preferring intermediate melanics. In Model 2, $\alpha$ prefer darks before intermediates and intermediates before pales.

with the difference of the log likelihood from that of the model with the highest likelihood. These log likelihood differences measure the relative "support" for the model with the highest likelihood (Edwards, 1972). Approximately, an increase in support of two log likelihood units represents a statistically significant improvement in fit of one model over another. In the case of a normally distributed estimate of a parameter, such as the estimate of the population mean, the two-unit support limits are exactly the same as limits of $\pm(2 \times$ standard error $)$,-roughly the 95 per cent fiducial limits.

The maximum likelihood estimation shows that Model $3 P$ has the highest likelihood, but there is no significant difference between any of the $P$ models, except for the obvious fact that Model 2 is rejected at a high level of significance (four units of support correspond to $P=0.00468$ for a normally distributed variate). The $P$ models are also a significantly better fit than the $R$ models with about two units more support. This is evidence for female choice, since we have argued that if some females have a lower threshold of response towards melanic males, this will produce preferential mating 
which precedes random mating and hence give rise to the $P$ models. Mating preferences in the $P$ models are almost twice those in the $R$ models: a total of about 38 per cent of females must express preferences to fit the data to the $P$ models.

We have shown that certain models of preferential mating are refuted by the greater support for other models, particularly Model 3P. But this does not prove that Model $3 P$ is sufficient to fit the data: significant heterogeneity may still remain after it has been fitted. Table 8 gives an analysis of $\chi^{2}$ after

\section{TABLE 8}

Analysis of $\chi^{2}$ when Model 3P is fitted to the data of table 1

Component of variation

Preferential mating with $\hat{\alpha}=0.0394 \hat{\beta}=0.3436$

Differences in breeding dates between periods $1948-62$ and 1973-79

Differences in proportions of phenotypes between periods 1948-62 and 1973-79

Residual heterogeneity

Total

*** This value of $\chi^{2}$ corresponds to $\mathrm{P}=0.000730$.

** This value of $\chi^{2}$ corresponds to $\mathrm{P}=0.0656$.

* This value of $\chi^{2}$ corresponds to $\mathrm{P}=0 \cdot 0165$.

The total $\chi^{2}$ is derived from two $3 \times 4$ contingency tables giving the numbers of dark, intermediate and pale males breeding in the successive weeks of the breeding season. The breeding season was divided into weeks as shown in table 1 , but for calculating $\chi^{2}$ the data of weeks 1 and 2 and 5 and 6 were lumped together to give two $3 \times 4$ tables, one for the period 1948-62 and the other for 1973-79. Thus there are 24 classes of data. The value of the total $\chi^{2}$ for 17 degrees of freedom was obtained by calculating expectations based upon:

(i) the total numbers breeding in each interval, which supplied three independent estimates of the proportions breeding in the four intervals;

(ii) the total numbers of the three phenotypes, which supplied two independent estimates of their proportions; and

(iii) the total numbers breeding in each period. Seven degrees of freedom are therefore lost from the total of 24 . The remaining 17 degrees of freedom and their corresponding values of $\chi^{2}$ are analysed in this table.

fitting Model 3P. When only the overall breeding dates and phenotypic frequencies are used to calculate the expectations in each class of table 1 , we obtain

$$
\chi_{17}^{2}=31 \cdot 685 \text {. }
$$

When Model $3 P$ is used to calculate the expectations, given the maximum likelihood estimates

$$
\hat{\alpha}=0.0394, \quad \beta=0.3436
$$

we then obtain

$$
\chi_{15}^{2}=17 \cdot 242
$$

the estimation of the two parameters having removed two more degrees of freedom. Table 8 shows that after further removing the effects of differences in breeding dates and phenotypic frequencies between the periods 1948-62 and $1973-79$, we are left with a residual $\chi^{2}$ for heterogeneity

$$
\chi_{10}^{2}=7 \cdot 478
$$

which is less than expectation. Model $3 P$ fits the data excellently well. 


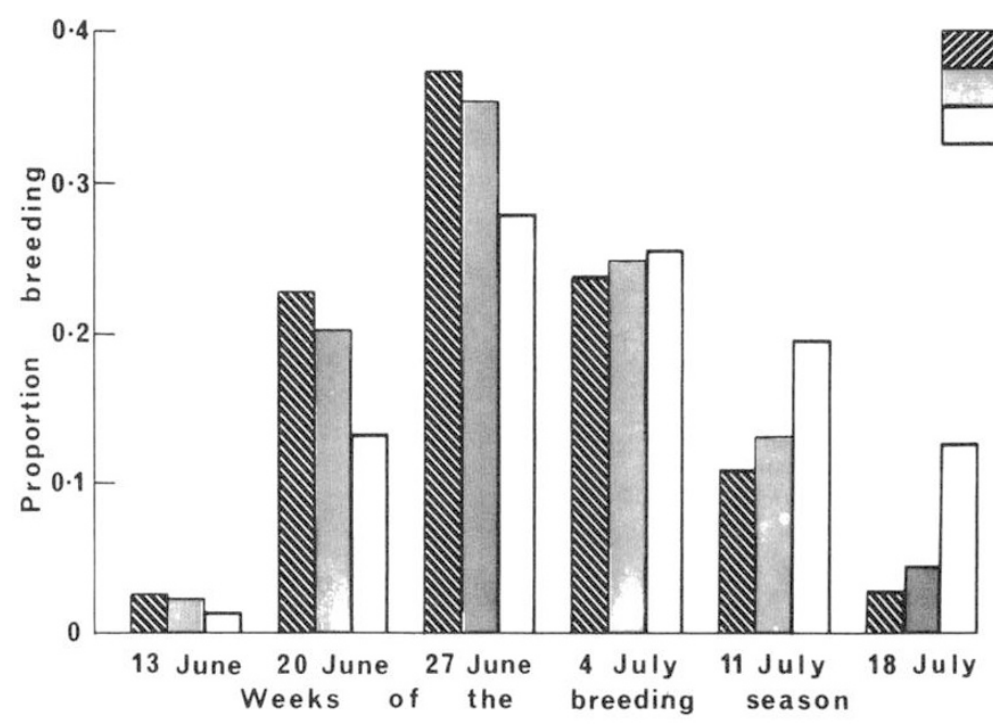

FIG. 1.-Hypothetical distributions of breeding dates according to Model $3 P$

The dates shown in the figure are the mid-week dates of each of the six weeks of the breeding season given in table 1 . The pale phenotypes represent the smallest proportion of the three phenotypes among males who are chosen to mate. In the figure, the frequency of each phenotype in each week has been divided by the total frequency of each phenotype, so that the proportions shown represent the probabilities of mating of each phenotype in each week.

Fig. 1 shows the hypothetical distributions of breeding dates as predicted by Model 3P. A much higher proportion of pale males are left unmated until the last week of the breeding season compared with intermediate and dark males. The darks always have the greatest chance of mating because the greatest proportion of females prefer them. Relative to their frequency, the darks always have the highest probability of finding a mate. Very few darks are left unmated at the start of the last week. Therefore they have the smallest variance in breeding date. The hypothetical variances in breeding dates (given in units of days ${ }^{2}$ ) are as follows:

$$
\begin{aligned}
\operatorname{var}(D) & =58 \cdot 2 \\
\operatorname{var}(I) & =63 \cdot 8 \\
\operatorname{var}(P) & =78.7
\end{aligned}
$$

The pales have the largest variance because of their flatter and more skewed distribution of breeding dates. All these differences disappear among birds breeding together for a second year (O'Donald, Wedd and Davis, 1974).

\section{(ii) Assortative mating}

Assortative mating would provide corroborative evidence for female choice, since males in direct competition are unlikely to compete only for females with phenotypes similar to the males themselves. Davis and O'Donald (1976a) reported data of assortative matings for intermediate Arctic Skuas. These data consisted of the numbers of matings between dark, 
intermediate and pale Arctic Skuas on the islands of Fair Isle and Foula in Shetland in 1975. When all new matings that took place on Fair Isle in the years $1973-79$ are analysed, the very significant assortative mating of 1975 is no longer found. 1975 must have been a freak year on Fair Isle, with a much higher than usual number of intermediate $x$ intermediate matings. Between 1973 and 1979 a total of 392 matings were observed with the following numbers of the mating types:

$\begin{array}{cccccc}\mathrm{D} \times \mathrm{D} & \mathrm{D} \times \mathrm{I} & \mathrm{D} \times \mathrm{P} & \mathrm{I} \times \mathrm{I} & \mathrm{I} \times \mathrm{P} & \mathrm{P} \times \mathrm{P} \\ 19 & 94 & 39 & 141 & 80 & 19\end{array}$

Assuming random mating of dark, intermediate and pale phenotypes, we obtain

$$
\chi_{3}^{2}=3 \cdot 584
$$

which corresponds to

$$
\mathrm{P}=0 \cdot 310
$$

and shows there is no significant deviation from random mating. When the data are classified into the three mating types I $\times I$, I $\times$ not-I and Not-I $\times$ NotI, then we obtain

$$
\chi_{1}^{2}=3.031, \quad \mathrm{P}=0.0817 .
$$

Although not significant, this would represent a mating preference of intermediates for intermediates given by the maximum likelihood estimate

$$
\hat{\beta}=0 \cdot 187 \text {. }
$$

In the Fair Isle data there is only a slight hint that darks and intermediates mate assortatively. But in data of matings in a number of different Shetland colonies of Arctic Skuas, in which the birds were classified simply as either melanic (dark or intermediate) or non-melanic (pale), the matings melanic $\times$ melanic and pale $\times$ pale were in significant excess compared with the expectations of random mating. As shown in table 9, assortative mating of melanics is certainly taking place. The assortative mating preference of melanic birds is estimated by

$$
\hat{\beta}=0.383 \text {. }
$$

This is almost exactly the same as the estimate of $\beta$ obtained by fitting Model $1 P$ to the data of the distributions of breeding dates. The closeness of the agreement is obviously co-incidental, the Fair Isle data alone giving a smaller, non-significant estimate of $\beta$. Models of the evolution of mating preferences predict that the preferential matings will become at least partly assortative (O'Donald, 1980a).

\section{(iii) Stability of the polymorphism}

More decisive evidence for female choice is provided by the general stability of the polymorphism. As I explained in the introduction, male competition gives rise to sexual selection with little or no frequencydependence (Charlesworth and Charlesworth, 1975; O'Donald, 1980a): it can only maintain a stable polymorphism if the heterozygotes are the best competitors. But female choice produces the "rare male" effect: this will maintain a polymorphism in both polygynous and monogamous species either by female preferences for two or more different male phenotypes, or 
TABLE 9

Assortative mating of melanic and pale phenotypes

(i) Model of assortative mating preference for melanics

$\begin{array}{ll}\text { Matings } & \text { Model } 1 \text { (Davis and O'Donald, 1976a) } \\ \text { Melanic } \times \text { melanic } & \beta u+u^{2}(1-\beta)^{2} /(1-\beta u) \\ \text { Melanic } \times \text { pale } & 2 u(1-u)(1-\beta) /(1-\beta u) \\ \text { Pale } \times \text { pale } & (1-u)^{2} /(1-\beta u)\end{array}$

Davis and O'Donald (1976a) described this and two other models of assortative mating and gave the maximum likelihood estimates of their parameters. In this model, the parameter $\beta$ is the preference of melanics for melanics: it corresponds to the parameter $\beta$ in Model $1 P$ (table 7). The parameter $u$ is the frequency of the melanic birds.

(ii) Numbers of matings and estimates of preference

$\begin{array}{lcccc} & \text { Fair Isle } & \text { Foula } & \text { Shetland } & \\ \text { Matings } & 1973-79 & 1975 & 1946-59 & \text { Total } \\ \text { Melanic } \times \text { melanic } & 254 & 144 & 218 & 616 \\ \text { Melanic } \times \text { pale } & 119 & 86 & 120 & 325 \\ \text { Pale } \times \text { pale } & 19 & 26 & 38 & 83 \\ \text { Estimate: } \hat{\beta} & 0.2159 & 0.3898 & 0.4434 & 0.3826 \\ \text { Variance: } \operatorname{var}(\hat{\beta}) & 0.03289 & 0.01550 & 0.008964 & 0.004876\end{array}$

(iii) Analysis of $\chi^{2}$ when the model is fitted to the data

$\begin{array}{lcc}\text { Component of variation } & \text { Value of } \chi^{2} & \text { Dfs } \\ \text { Preferential mating for melanics } & 19 \cdot 2720^{* * *} & 1 \\ \text { with } \hat{\beta}=0 \cdot 3826 & 11 \cdot 0010^{* *} & 2 \\ \text { Differences in proportions of phenotypes } & 1.4882 & 2 \\ \text { Residual heterogeneity } & 31 \cdot 7612^{*} & 5 \\ \text { Total } & \end{array}$

*** This value of $\chi^{2}$ corresponds to $\mathrm{P}=1.13 \times 10^{-5}$.

** This value of $\chi^{2}$ corresponds to $\mathrm{P}=0.00408$.

* This value of $\chi^{2}$ corresponds to $\mathrm{P}=6 \cdot 62 \times 10^{-6}$.

This analysis of $\chi^{2}$ should be compared with that given in table 8 .

by a preference for a phenotype that natural selection disfavours (O'Donald, $1974,1980 a, 1980 b$ ). In the Arctic Skua, the homozygous dark males have the greatest advantage: in new pairs they breed somewhat earlier than the heterozygous intermediates and much earlier than the homozygous pales; darks have the greatest reproductive success (O'Donald, Wedd and Davis, 1974; O'Donald and Davis, 1977). There is no possibility, therefore, that sexual selection might produce a heterozygous advantage in the population on Fair Isle.

The polymorphism in the Arctic Skua has shown remarkable stability in Shetland over the period 1948-79, which covers three generations. The phenotypic frequencies show a cline of increasing proportions of pales from south to north. Stable clines can be produced by a balance between selection and migration, but in the Arctic Skua this is unlikely. The birds generally return to breed in their natal colony. Migration occurs only rarely and only between adjacent colonies with similar phenotypic frequencies; there appears to be no migration between the widely separated colonies that vary in clinal frequency. The cline is probably determined by variation from 
south to north in the balance of selection at each point. In Model 3P, the sexual selection in favour of dark and intermediate males would ultimately produce a homozygous dark population; but sexual selection appears to be balanced by natural selection in favour of the pale homozygote. On average, pale birds mature about half a year earlier than darks and intermediates: being younger when they breed, they gain an advantage from their greater chance of surviving to reproductive age. Sexual and natural selection are thus in opposition. Since this form of natural selection cannot be frequencydependent, the stability of the polymorphism must be determined by frequency-dependent sexual selection and hence by female choice.

\section{(iv) Male experience}

As the last piece of evidence in favour of female choice, we have already noted that males with previous breeding experience are not significantly quicker than new males in finding new mates (table 4). Yet if male competition were the cause of success in finding mates, we should expect that males who had bred before would have gained experience and hence greater success. If females exercise a choice, however, preferred males may all be equally successful, regardless of their previous experience.

\section{Conclusions}

The evidence for female choice that I have presented in this paper is not entirely conclusive-even though it is strongly supported by four different and independent sets of observations. The breeding dates of the males could be explained however by a special form of male competition: if males competed for large territories, those with the larger territories might have the greater chance of mating. The melanic males do have larger territories than the non-melanics and the difference in territory size is sufficient to explain the mean difference in breeding dates (Davis and O'Donald, 1976b; O'Donald, 1980a). But the differences in territory size are based on small numbers and are not significant. Observations on changes of mate show that females do not select males by the sizes of their territories (Davis and O'Donald, $1976 b$ ). The excellent fit of the $P$ models to the data of breeding dates is most simply explained by female choice. Assortative mating, which certainly occurs in the Arctic Skuas of Shetland, is also most simply explained by female choice. Assortative mating would only explain part of the preferential mating, but this is precisely what models of the evolution of mating preferences predict: as the preferences evolve, the genes for the preference become associated in linkage disequilibrium with the gene for the preferred character and the preferential mating becomes partly assortative. The stability of the polymorphism supports female choice. Unless male competition were itself frequency-dependent, it could not give rise to stable polymorphisms without heterozygous advantage. Frequencydependent competition seems incredible but has not been excluded. Male competitive performance should improve with experience, but experienced males are not more successful than new males: female choice will benefit new and experienced males equally. These four lines of evidence-the fit of the models, the assortative mating, the stability of the polymorphism and the success of new and experienced males-all give strong support to the theory 
of female choice. In each case, an explanation in terms of male competition would require additional postulates, some of which are highly implausible.

Thus we may conclude that female Arctic Skuas prefer to mate with the dark and intermediate males. These males, who are thus the objects of female preferences, breed at an earlier mean date than the pale males. They gain an advantage over the pales, exactly as Darwin had postulated, because early pairs are more successful than late pairs in the number of chicks they rear to fledging. The advantage they gain in this way applies only to new pairs in which the males have changed their mates. The selective advantage in the population as a whole depends on the proportion of new pairs formed as a result of the sexual selection. Intermediates are at a slight disadvantage to darks and pales at a much greater disadvantage. The selective coefficients measuring these relative selective disadvantages are given by

$$
s_{\mathrm{I}}=0.014, \quad s_{\mathrm{p}}=0.063 .
$$

The polymorphism is stable because the pales are younger when they breed for the first time and thus have a greater probability than darks and intermediates of returning to breed. This natural selection balances the frequency-dependent sexual selection against pale.

\section{REFERENCES}

CHARLESWORTH, D., AND CHARLESWORTH, B. 1975. Sexual selection and polymorphism. Amer. Natur., 109, 465-470.

DARwIN, C. R. 1871. The Descent of Man and Selection in Relation to Sex. John Murray, London.

DA VIS, J. W. F., AND O'DONALD, P. 1976a. Estimation of assortative mating preferences in the Arctic Skua. Heredity, 36, 235-244.

DAVIS, J. W. F., AND O'DONALD, P. 1976 . Territory size, breeding time and mating preference in the Arctic Skua. Nature, 260, 774-775.

EDWARDS, A. W. F. 1972. Likelihood. Cambridge University Press, Cambridge.

EHRMAN, L., AND SPIESS, E. B. 1969. Rare type mating advantage in Drosophila. Amer. Natur., 103, 675-680.

O'DONALD, P. 1972. Natural selection of reproductive rates and breeding times and its effect on sexual selection. Amer. Natur., 106, 368-379.

O'DONALD, P. 1974. Polymorphisms maintained by sexual selection in monogamous species of birds. Heredity, 32, 1-10.

O'DONALD, P. 1976. Mating preferences and their genetic effects in models of sexual selection for colour phases of the Arctic Skua. Population Genetics and Ecology, ed. S. Karlin and E. Nevo, pp. 411-430. Academic Press, New York.

O'DONALD, P. $1977 a$. Theoretical aspects of sexual selection. Theor. Pop. Biol, 12, 298-334.

O'DONALD, P. $1977 \mathrm{~b}$. Mating preferences and sexual selection in the Arctic Skua. II. Behavioural mechanisms of the mating preferences. Heredity, 39, 111-119.

O'DONALD, P. 1978a. Theoretical aspects of sexual selection: a generalized model of mating behaviour. Theor. Pop. Biol., 13, 226-243.

O'DONALD, P. 1978b. Rare male mating advantage. Nature, 272, 189.

O'DONALD, P. 1979. Theoretical aspects of sexual selection: variation in threshold of female mating response. Theor. Pop. Biol., 15, 191-204.

O'donald, P. 1980a. Genetic Models of Sexual Selection. Cambridge University Press, Cambridge.

O'DONALD, P, 1980 $\mathrm{b}$. Genetic models of sexual and natural selection in monogamous organisms. Heredity, 44, 391-415.

O'DONALD, P., AND DAVIS, J. W. F. 1975. Demography and selection in a population of Arctic Skuas. Heredity, 35, 75-83.

O'DONALD, P., AND DAVIS, J. W. F. 1977. Mating preferences and sexual selection in the Arctic Skua. III. Estimation of parameters and tests of heterogeneity. Heredity, 39, 121-132.

O'DONALD, P., WEDD, N.S., AND DAVIS, J. W. F. 1974. Mating preferences and sexual selection in the Arctic Skua. Heredity, 33, 1-16.

SPIESS, E. B., AND EHRMAN, L. 1978. Rare male mating advantage. Nature, 272, 188-189. 